\title{
Charles Waldegrave
}

\section{Old and Poor or Old and Cared for? Some policy reflections on data from the first two waves of NZLSA}

Introduction

It is customary in New Zealand policy circles to assume that older citizens are financially protected by New Zealand Superannuation (NZS) and their high rates of home ownership. Furthermore, it is assumed that families with children are much more at risk of living below one or more of the various poverty thresholds. The evidence supports this belief and there is, of course, an urgent need to address child poverty. However, the status of NZS and home ownership as protective factors for older people in the years

Charles Waldegrave is the leader of the Family Centre Social Policy Research Unit in Lower Hutt, Wellington and coordinator of the Family Centre Pākehā (European) section. He is a principal investigator in the New Zealand Longitudinal Study of Ageing (NZLSA) research project. ahead is not guaranteed. They could both be substantially eroded, turning two of New Zealand's fine policy achievements into a disaster if they are not properly attended to. So the critical policy challenge is to eliminate child poverty, while preserving the gains achieved for older New Zealanders. This requires considerable policy focus, given the demographic changes that New Zealand is currently undergoing.

Ageing is a critical driver of the demographic changes taking place in New Zealand, as the post-war baby boomers populate the 65-plus age group in large numbers. Projections from Statistics New Zealand (middle series) indicate that 100,000 people aged 65 and over will be added to the population every five years from 2011 to 2036 (Statistics New Zealand, 2007). The 2013 census 
has shown that that process has well and truly begun. During the intercensal period 2006-2013 the population aged 60-64 increased by $30 \%$, those aged $65-$ 69 by $32 \%$ and those 85 years and over by 29\% (Statistics New Zealand, 2013a). The largest increase is expected to take place in the decade 2021-2031, when an extra 276,000 people are projected to move into the older age group (Statistics New Zealand, 2005, 2007). The percentage of those aged 65 and over has increased from $12 \%$ in 2006 to $14 \%$ in 2013 , and is expected to comprise a quarter of the population by 2051 .

This extraordinary demographic shift is largely driven by post-war fertility rates, advances in medical science, and people living in healthier ways and consequently living longer. Life expectancy at birth in New Zealand for women is 83 years and for men 79 years. This represents an increase of seven years for women and nine years for men over the three decades 1980-82 to 2010-12 (Statistics New Zealand, 2014). Policy experts have had a field day talking up the threats to the New Zealand economy and our way of life, characterising the population changes as a silver tsunami. The fears have centred largely on the cost of NZS and health costs, as there will be fewer people of working age to support a larger number of older citizens.

It is not the purpose of this article to evaluate these arguments, but suffice to say that a number of the assumptions of the gloom merchants fail to take into account a range of other factors, including the increasing numbers of people 65 and over in the labour market and paying taxes; the fact that the big spend on health tends to be at the end of life, and this has been delayed rather than elongated; the substantial contribution in family care and voluntary hours made by older citizens; and the simple matter that many of the risks can be planned for and mitigated.

A tsunami implies a natural disaster with profoundly destructive consequences. But need we look at it that way? The wave is growing but it stretches over many years. It can be planned for and it will create its own opportunities. As the Economist so cleverly put it, smart policy may enable us to ride the silver wave with all the agility of bronzed surfers.

The purpose of this article is to present an analysis of the income, poverty, asset accumulation, housing tenure and well-being data in the first two waves of the New Zealand Longitudinal Study of Ageing (NZLSA) in order to better understand the living standards and experience of well-being for the total sample 50 years and over, and separately for those 65 years and over.

\section{Income, poverty and housing}

Older people in New Zealand are generally considered to have an adequate, if not a high, standard of living when compared with those living in similar countries. This is largely because of a universal pension policy, a history of home ownership, and a reasonably accessible, though by no means perfect, health service. NZS is universal and indexed to movements of the average wage. Hovering around $50 \%$ of median disposable household income, it currently sits very close to the OECD poverty line and is usually just above it. It is, however, well below the European Union income indicator of social exclusion, which is $60 \%$ of median household disposable income.

NZS is the right of New Zealand citizens and permanent residents (certain residential criteria apply) on reaching 65 years of age, and is gender neutral in the sense that work history and the level of income and contributions do not apply as they do in most other countries. Until recently New Zealand has had a high level of home ownership, which has allowed the vast majority of older people to live in mortgage-free houses.

When non-income indicators of material living standards are used in surveys, a picture of New Zealanders' material circumstances emerges alongside income circumstances. These surveys include questions about ownership of household durables and their quality, the ability to keep the house warm and to pay the bills, to afford fruit and vegetables, adequate clothing, to pay for a night out, and so on. Interestingly, older New Zealanders (aged 65 plus) have the most favourable distribution of living standards of all age groups. In the most recent survey carried out by the Ministry of Social Development, applying the Economic Living Standards Index (ELSI), the older population has the highest mean score and the lowest hardship rate (Perry, 2009). This probably reflects the combined effect of NZS and their asset accumulation, including their home and other savings. The positive impact of NZS is demonstrated by hardship figures: for the 45-64-year-olds the hardship rate is $23 \%$, higher than that of the 65 plus group (4\%), despite the fact the 45-64-year-olds have the highest overall incomes.

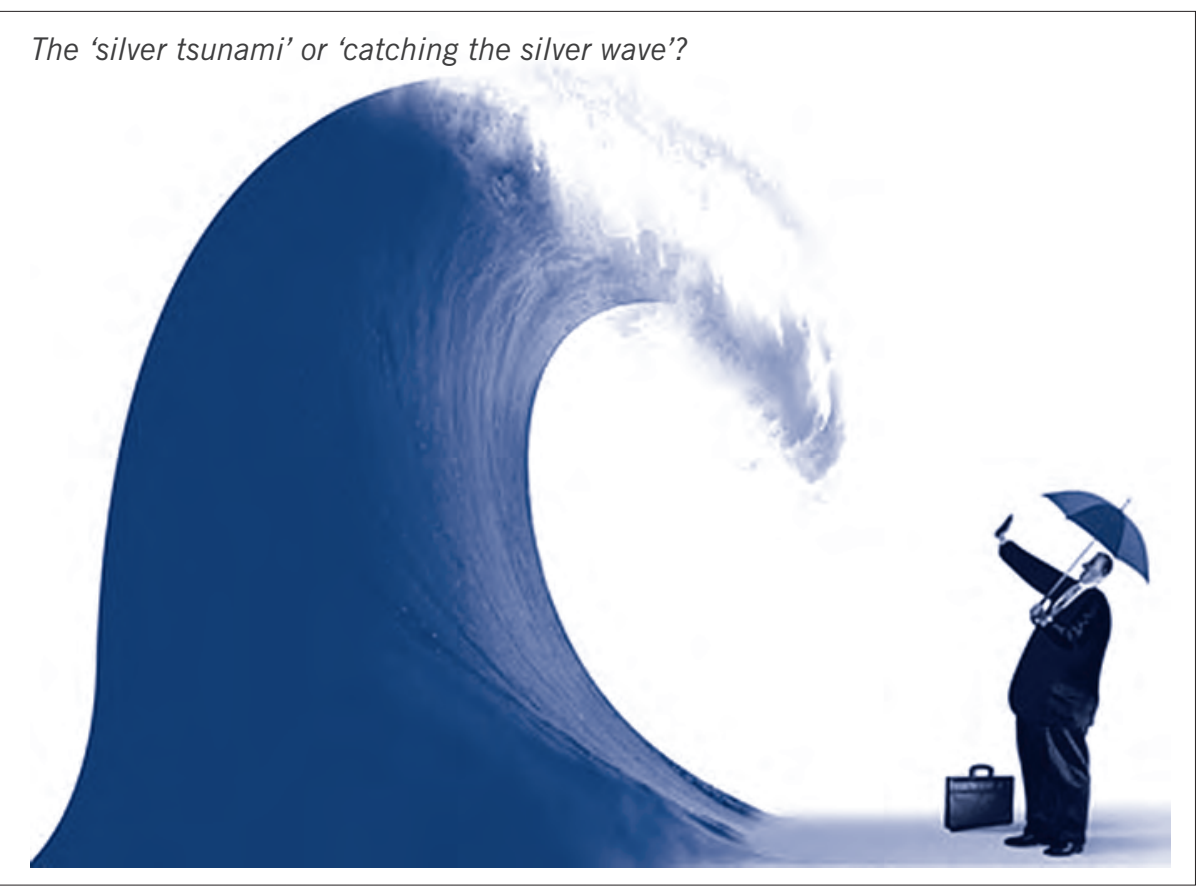

4 Feb 2010 | From the Economist print edition 
Table 1: Gross personal and household median income by age bracket waves 1 \& 2

\begin{tabular}{lrr}
\hline Median Income & 2010 & 2012 \\
\hline $50-87$ years Personal & $\$ 40,232$ & $\$ 34,183$ \\
$65-87$ years Personal & $\$ 24,025$ & $\$ 26,000$ \\
& & \\
$50-87$ years Household & $\$ 67,600$ & $\$ 62,980$ \\
$65-87$ years Household & $\$ 39,634$ & $\$ 46,000$ \\
\hline
\end{tabular}

Source: New Zealand Longitudinal Study of Ageing

It is of considerable interest to policy makers, and of great concern to older people and their families, that they have sufficient economic resources to maintain a reasonable standard of living. Poverty studies have demonstrated that the older population are better protected from poverty and hardship than other population groups (Waldegrave, Stephens and King, 2003; Perry, 2013). This does not mean they are well off by comparison, but that there are fewer people in serious poverty at the lower income end. These same poverty studies also demonstrate the impact of housing tenure. The numbers of households with older people living below the poverty threshold drops considerably when housing costs are taken into account. This is largely due to the lower housing costs for the vast majority who are mortgage-free. Renters are much more likely to be in poverty than home owners for all age groups.

In New Zealand Waldegrave and Cameron (2007) reported positive associations between income and wellbeing among older people. Research in countries similar to New Zealand, including Australia (Headley and Wooden, 2004), the UK (Netuveli et al., 2006; Gabriel and Bowling, 2004) and Sweden (Pinquart and Sorensen, 2000; Borg, Hallberg and Blomqvist, 2006; Berg et al., 2009), has found similar results, as has a Taiwan study (Hsu, 2010). Higher levels of income, financial satisfaction and wealth were associated with a better quality of life in old age. Netuveli et al. noted that 'perceiving financial circumstances to be poor had a very high effect on lowering quality of life scores ... while owning cars and being on the high end of income distribution improved quality of life scores' (Netuveli et al., 2006, p.360). However, they also found that this association changed over time and was less significant for those 75 years and older. Worrying about finances may reduce quality of life among older people, as can financial restrictions on activities or access to basic resources and necessities, such as medication or medical appointments (Gabriel and Bowling, 2004; Pinquart and Sorensen, 2000).

Other researchers have found a less clear relationship between quality of life and financial security, satisfaction or income. Wilhelmson et al. (2005), in a Swedish study, found that finances and worrying about finances were the least mentioned factors in a quality of life survey among the elderly, and were cited by only $5 \%$ of men and $10 \%$ of women in response to an open-ended question 'what is quality of life?' Similarly, Depp and Jeste (2006), in a review of 28 studies of successful ageing, found that income and education were not consistently associated with successful ageing.

As with income studies, Kohli, Künemund and Zähle (2005) in their analysis of the Survey of Health, Ageing and Retirement in Europe (SHARE) database noted that home ownership was associated with larger and better homes, and, because mortgage payments usually decrease over time, it contributed to economic and emotional security. Similarly, in a large British study of the association of quality of life in old age with socio-economic position, Breeze et al. (2004) found that, among respondents who lived independently, owner-occupiers were less likely to have poor quality of life. Changing tenure to renting in later years, after most of one's adult life had involved owner-occupation, carried significantly greater chances for three out of five bad quality of life outcomes, while movement from renting to ownership, by contrast, reduced the chances of two of the bad quality of life outcomes.

In this study we wanted to see: if the same patterns of income and asset accumulation noted above occurred in the NZLSA database; how extensive poverty is among those aged 50 years and over; the extent of housing tenure differences; and the relationship of all these to older people's experience of well-being and quality of life. Furthermore, what are the implications of these results for future well-being?

\section{Methodology}

The New Zealand Longitudinal Study of Ageing began wave 1 with a national random sample of 3,317 New Zealanders aged between 50 and 84 in 2010, and retained 3,015 participants for the second wave in 2012. A comprehensive postal questionnaire containing scales and questions on general health, social support, care-giving roles, financial wellbeing, neighbourhood characteristics and demographic information was sent to all participants. Among the sets of questions used in this study were two well-being (quality of life) scales, a health scale with physical and mental health components, and a depression scale. These were WHOQoL-8, ${ }^{1}$ CASP- $12,{ }^{2}$ SF- $12^{3}$ and the CES-D-10 ${ }^{4}$ scales. Questions concerning income and housing tenure were asked, ${ }^{5}$ and three poverty measures were used.

\section{Income}

The results in Table 1 show median personal and household incomes for people 65-87 to be much lower in both waves 1 and 2 than for the total sample (5087 years). In 2012 nearly $80 \%$ of median personal income for the 65-87 group was derived from NZS, which demonstrates how much the older population depends on it. Around $60 \%$ of household income was derived from NZS.

The cushioning effect of NZS is also demonstrated in Table 1. The total sample lost income over the two waves, probably because of the ongoing impact of the global financial crisis. However, it is interesting to note that if the age 65-87 sub-sample is looked at independently the trend runs in the opposite direction, as their incomes increased. This is probably because a substantial amount of their income derives from NZS, which is benchmarked to wage rises and protected from most of the impact of market fluctuations. 


\section{Poverty}

Three income poverty thresholds were applied to the data in order to determine how many households were experiencing hardship. These were:

- the OECD $50 \%$ of median, equivalent, disposable household income measure;

- the European Union $60 \%$ of median, equivalent, disposable household income as applied in the EU as the income indicator of social exclusion;

- the New Zealand constant value threshold benchmarked to $60 \%$ of the 2007 median, adjusted for the cost of living for each subsequent year. Housing costs are estimated to be $25 \%$ of household income (Perry, 2013).

For people aged 65-87, the NZLSA data show a decrease in poverty between 2010 and 2012 on the two totally relative measures, and an increase in the constant value after-housing-costs measure. Table 2 shows that for the $50 \%$ of median household disposable income threshold, poverty decreased from $14.5 \%$ to $11.8 \%$, and for the $60 \%$ measure poverty decreased from $36.7 \%$ to $30.1 \%$ over the two-year period. The constant value measure that takes housing costs into account demonstrated an increase in poverty over the same period from $17.5 \%$ to $21.1 \%$.

The impact of high home ownership and consequent lower housing costs among the older population is illustrated in the third measure. The poverty levels are considerably lower than for the second measure, which is simply based on $60 \%$ of median household income, without adjusting for housing costs. For the total sample of ages 50-87 years, households below the $50 \%$ of median poverty threshold decreased between 2010 and 2012 from $12.5 \%$ to $11.2 \%$. However, for the $60 \%$ mark the proportion of households in poverty increased $(22.6 \%$ to $26.2 \%$ ), and for the third measure the proportion also increased, from $16.3 \%$ to $19.7 \%$.

The poverty rates of the sub-sample of 65-plus years were higher than for the total sample on every measure, although in some instances the differences were small. Despite this, as noted above the
Table 2: percentage of 50- to 87 -year-olds below different poverty thresholds

\begin{tabular}{lrrrr}
\hline & \multicolumn{2}{c}{2010} & \multicolumn{2}{c}{2012} \\
\hline Equivalent, disposable, household income & $50-87$ & $65-87$ & $50-87$ & $65-87$ \\
\hline $50 \%$ of median & 12.5 & 14.5 & 11.2 & 11.8 \\
$\begin{array}{l}\text { 60\% of median } \\
\text { 60\% of constant value threshold after }\end{array}$ & 22.6 & 36.7 & 26.2 & 30.1 \\
housing costs estimated at 25\% of income & 16.3 & 17.6 & 19.7 & 21.1 \\
\hline
\end{tabular}

Source: New Zealand Longitudinal Study of Ageing

incidence of poverty for this older group actually decreased on the straight income measures between the two waves. It was the third measure, which takes housing costs into account, that increased, probably reflecting a proportional climb in housing costs in 2012.

\section{Housing tenure}

Home ownership for the total sample of 50-87-year-olds was very high in both waves, as the owned with and without a mortgage and the family trust categories in Figure 1 show. These three categories totalled $90 \%$ in 2010 and $91 \%$ in 2012 . Only $8.5 \%$ were renting or boarding in 2010 and $7.7 \%$ in 2012.

\section{Well-being and health}

We tested the relationships for the total sample between those above and below all three poverty thresholds in waves 1 and 2 with well-being and quality oflifemeasures, applying two well-used, internationallyapplied scales, WHOQoL-8 and CASP12. WHOQoL-8 focused primarily on

questions of satisfaction, whereas CASP-12 identifies broader areas relating to control, autonomy, self-actualisation and pleasure. We found significant relationships in both waves between all three poverty measures and the well-being scales, with substantially lower well-being scores for those below the poverty threshold. ${ }^{6}$ Interestingly, the WHOQoL- 8 and CASP12 well-being responses both produced similar results.

We then went on to test the relationship of those above and below the $60 \%$ constant value poverty threshold applying the SF-12 physical and mental health scales and the CES-D-10 depression scale for both waves 1 and 2. Again, we found significant relationships between the poverty threshold and both the health and depression scales, with substantially lower health and higher depression scores for those below the poverty threshold. ${ }^{7}$

We decided to further investigate the impact of poverty on well-being by estimating a linear regression, using wellbeing as the dependent variable and data

Figure 1: Housing tenure in 2010 and 2012

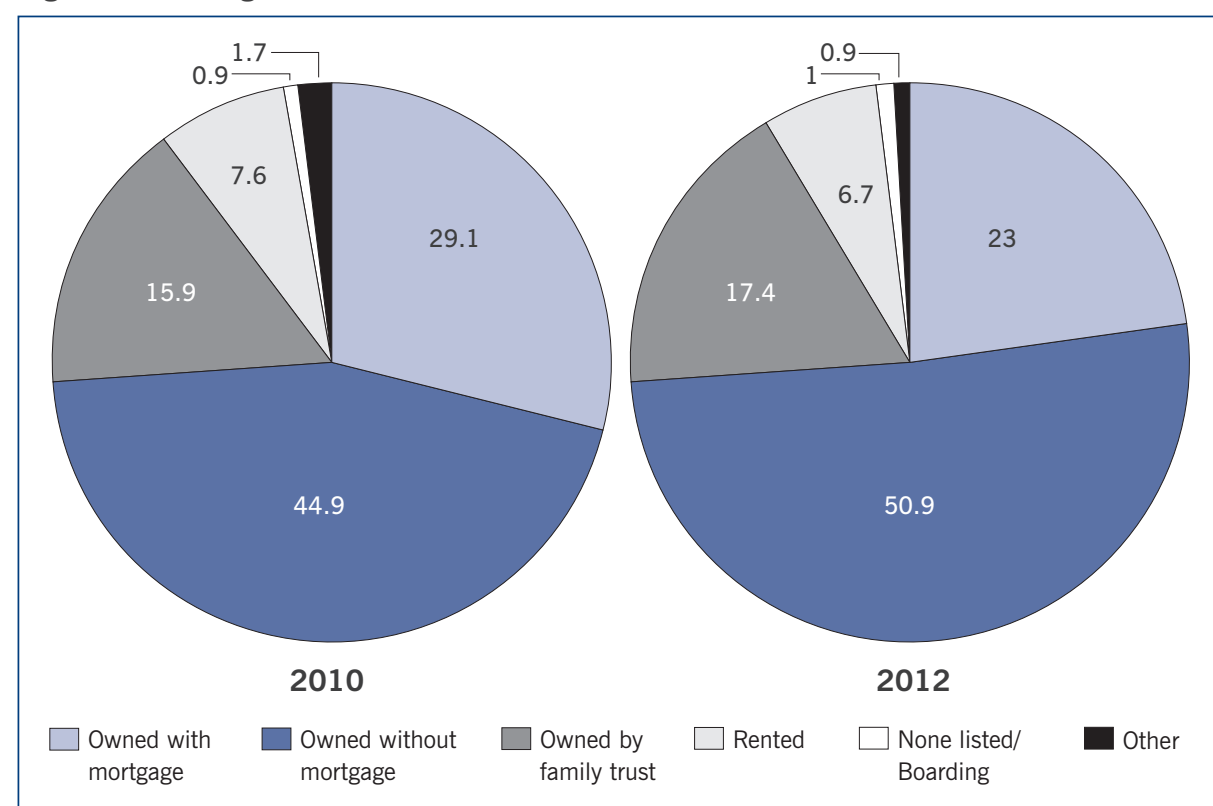

Source: New Zealand Longitudinal Study of Ageing 
Table 3: Private dwelling by household tenure (\%)

\begin{tabular}{lrr}
\hline Census & $\begin{array}{r}\text { Owner- } \\
\text { occupied }^{11}\end{array}$ & Rented \\
\hline 1991 & 73.6 & 23.1 \\
1996 & 70.5 & 25.6 \\
2001 & 67.8 & 29.0 \\
2006 & 66.9 & 28.9 \\
2013 & 64.8 & 31.2 \\
\hline
\end{tabular}

Source: Statistics New Zealand, 2013b

we had on poverty, asset accumulation and housing tenure as the three independent variables, for waves 1 and 2. The results applying the CASP-12 scale showed a significant negative association between poverty and well-being and a significant positive association between asset accumulation and well-being. ${ }^{8}$ Those below the poverty threshold and those with fewer assets had lower wellbeing scores.

Finally, we estimated two linear regressions using physical health as the dependent variable for the first and the depression scale for the second, and the three factors as the independent variables, for waves 1 and 2. The results applying the SF-12 physical component and CES-D-10 scales showed similar significant associations with poverty and asset accumulation. The association with housing tenure was not significant for physical health, ${ }^{9}$ and significant, but not strong, for depression. ${ }^{10}$

\section{Discussion and policy implications}

The well-being or quality of life of citizens is a primary goal of social and economic policy. In this study two quite different well-being/quality of life scales were applied and both demonstrated similar results, showing that when older people drop below a recognised poverty threshold their quality of life reduces.

Good health is another major goal of social policy, and ill-health impacts severely on fiscal policy and government costs. Likewise, depression is a state of mind that leaves people more susceptible to mental and physical ill-health and a negative view of their quality of life. These results reveal the negative impact of poverty on health status.

There are consistent, statistically significant relationships between being below a poverty threshold and the reduction of well-being/quality of life, physical and mental health and depression. Low incomes and low asset accumulation were consistently associated with low levels of well-being, low levels of physical and mental health and higher levels of depression. The housing tenure variable was not as consistent, but it did show an association with depression.

The income and poverty results in this study show that a not insubstantial number of older citizens drop below each of the standard poverty thresholds. The numbers below the threshold range from $12 \%$ to around a third depending which measure is applied. Furthermore, the median income results demonstrate how reliant many of those above the lines are on NZS for their current living standards. Given the substantial demographic shift that New Zealand and most countries are currently undergoing, there is cause for concern. By 2050 around a quarter of the population are expected to be 65 years or older. Questions concerning the savings behaviour of New Zealanders and the sustainability of NZS are being raised (Stroombergen, 2013; Commission for Financial Literacy and Retirement Income, 2013). There are some serious threats and challenges for the 'baby boomers' as they age, and it is not a good omen that the New Zealand government has taken a six-year holiday from contributing to the New Zealand Superannuation Fund. The fund was designed specifically to enable a smoother transition to a time when a greater proportion of GDP will have to be set aside to support a vastly increased number of superannuitants.

Nor does the trend of reducing home ownership, as displayed in Table 3, offer any comfort. Mortgage-free homes have been critical to preventing many older New Zealanders from dipping below the poverty threshold when they cluster so close to the internationally-set poverty lines.

The census housing tenure data demonstrate the emerging problem. In future a larger number of older people will not own their own home and are likely to be much more subject to rental market prices and fluctuations than older citizens today. Table 3 demonstrates a decrease of almost $10 \%$ in home ownership over the last 22 years. There is no sign that this trend is arresting. Furthermore, the current provision of social housing in New Zealand is not adequate to protect the numbers of older people expected to be renting in their later years (Housing Shareholders Advisory Group, 2010).

If older people drop below the poverty threshold in larger numbers in the future, it can be expected that their quality of life will reduce and their health will deteriorate. Currently we have a very serious problem with the levels of child poverty in New Zealand, and every effort needs to be made to address it. It is important, though, that the quality of life older people have experienced in New Zealand is not compromised by neglect of the threats that lie ahead. People at both ends of the life cycle require attention because they are so much more vulnerable than most of the population between them. Policies for older New Zealanders need to focus on income stability through a combination of saving incentives and ensuring NZS maintains its value relative to average earnings. Policies also need to focus on future housing need as home ownership declines. KiwiSaver is making an important contribution to savings. Attention could also be given to making NZS sustainable by a resumption of contributions to the New Zealand Superannuation Fund. Finally, the stock of social housing will need to be built up substantially if it is to have the capacity to provide adequate accommodation for older people who can be expected to require it in the future.

\footnotetext{
WHOQOL-8 is a World Health Organisation quality of life instrument that assesses subjective well-being. Eight questions inquire into participants' satisfaction with various aspects of their health and physical and social lives. A five-point scale is used, ranging from very satisfied to very dissatisfied.

2 CASP-12 is a quality of life measure of well-being developed for older people which spans four domains of control, autonomy, self-realisation and pleasure (hence CASP). Twelve questions inquire into the four domains, using a four-point scale ranging from often to never.

3 The SF-12 is a generic health status measure of health outcome in a wide variety of patient groups and social surveys. It was developed from the SF-36 to enhance response rates by reducing patient burden without decreasing reliability. The 12 -item questionnaire has two components: a physical component summary score (PCS) and a mental health component summary score (MCS)

4 The CES-D-10 scale is a short, self-report scale designed to measure depressive symptomatology in the general population. The items of the scale are symptoms associated with depression which have been used in previouslyvalidated longer scales.

5 Care was taken to separate pre- and post-tax incomes, and individual and household incomes. A question on
} 
the composition of each household was asked, enabling equivalence scales to be used. The scale applied to the household income data was the Jensen Revised Equivalence Scales (Jensen, 1988), which are the most commonly used in New Zealand. The question on housing tenure offered three ownership options (owned without a mortgage, owned with a mortgage and owned by a family trust) and three nonownership options (renters, boarders and other).

$650 \%$ of median, equivalent, disposable household income T-test statistic had a p-value of $<0.001$, as did the other two measures for both well-being scales.

7 SF-12 physical health - T-test statistic had a p-value of
$<0.001$, as did the SF-12 mental health and the CES-D-10 depression scores

8 The F-test statistic had a p-value of $<0.001$ for both waves. This tested the whole model. The T-test of significance of the poverty and asset accumulation tenure coefficients in front of each variable had a $p$-value of $<0.001$ for both waves. However, the housing tenure coefficient showed no significant relationship in 2010 and 2012.

9 The F-test statistic had a p-value of $<0.001$ for both waves testing the whole model. The T-test of significance of the poverty and asset accumulation coefficients in front of each variable had a $\mathrm{p}$-value of $<0.001$ for both waves. However, the housing tenure coefficient showed no significant relationship in 2010 and 2012.

10 The F-test statistic had a p-value of $<0.001$ for both waves testing the whole model. The T-test of significance of the poverty and asset accumulation coefficients in front of each variable had a $p$-value of $<0.001$ for both waves. The housing tenure coefficient showed a p-value of 0.001 in 2010 and 0.036 in 2012 .

11 Includes dwellings owned by individuals or held in a family trust (from 2006).

\section{References}

Berg, A.I., L. Hoffman, L.B. Hassing, G.E. McClearn and B. Johansson (2009) 'What matters, and what matters most, for change in life satisfaction in the oldest-old? A study over 6 years among individuals 80+', Aging and Mental Health, 13 (2), pp.191-201, doi: $10.1080 / 13607860802342227$

Borg, C., I. Hallberg and K. Blomqvist (2006) 'Life satisfaction among older people $(65+)$ with reduced self-care capacity: the relationship to social, health and financial aspects', Journal of Clinical Nursing, 15, pp.607-18

Breeze, E., D.A. Jones, P. Wilkinson, A.M. Latif, A. Bulpitt, A. and E. Fletcher (2004) 'Association of quality of life in old age in Britain with socioeconomic position: baseline data from a randomised controlled trial', Journal of Epidemiology and Community Health, 58, pp.667-3

Casey, B. and A. Yamada (2002) Getting Older, Getting Poorer? A study of the earnings, pensions, assets and living arrangements of older people in nine countries, OECD Labour market and social policy occasional paper 60, Paris: OECD

Commission for Financial Literacy and Retirement Income (2013) Focusing on the Future: report to Government, Wellington: Commission for Financial Literacy and Retirement Income

Department of the Prime Minister and Cabinet (2008) Families in Australia 2008, Canberra: Department of the Prime Minister and Cabinet

Depp, C.A. and D.V. Jeste (2006) 'Definitions and predictors of successful aging: a comprehensive review of larger quantitative studies', American Journal of Geriatric Psychiatry, 14, pp.6-20

Gabriel, Z. and A. Bowling (2004) 'Quality of life from the perspectives of older people', Ageing and Society, 24 (5), pp.675-91, doi:10.1017/ S0144686X03001582

Headley, B. and M. Wooden (2004) 'The effects of wealth and income on subjective well-being and ill-being', Economic Record, 80 (special issue, September), pp.S24-33

Housing Shareholders Advisory Group (2010) Home and Housed: a vision for social housing in New Zealand, Wellington: Housing Shareholders Advisory Group

Hsu, H-C. (2010) 'Trajectory of life satisfaction and its relationship with subjective economic status and successful aging', Social Indices Research, 99, pp.455-68, doi 10.1007/s11205-010-9593-8

Kohli, M., H. Künemund and T. Zähle (2005) 'Housing and living arrangements', in A. Borsch-Supan et al., Health, Ageing and Retirement in Europe: first results from SHARE, Mannheim: Mannheim Research Institute for the Economics of Aging

Netuveli, G., R.D. Wiggins, Z. Hildon, S.M. Montgomery and D. Blane (2006) 'Quality of life at older ages: evidence from the English longitudinal study of aging (wave 1)', Journal of Epidemiology Community Health, 60, pp.357-63, doi: 10.1136/ jech.2005.040071

Perry, B. (2009) Non-income Measures of Material Wellbeing and Hardship: first results from the 2008 New Zealand Living Standards Survey, with international comparisons, working paper 01/09, Wellington: Ministry of Social Development

Perry, B. (2013) Household Incomes in New Zealand: trends in indicators of inequality and hardship 1982 to 2012, Wellington: Ministry of Social Development

Pinquart, M. and S. Sorensen (2000) 'Influences of socioeconomic status, social network, and competence on subjective well-being in later life: a meta-analysis', Psychology and Ageing, 15 (2), pp.187-224, doi: 10.1037//0882-7974.15.2.187

Statistics New Zealand (2006) Demographic Trends 2005, Wellington: Statistics New Zealand

Statistics New Zealand (2007) National Population Projections: 2006 (base)-2061, Wellington: Statistics New Zealand

Statistics New Zealand (2013a) Census QuickStats about national highlights: age and sex, http://www.stats.govt.nz/Census/2013census/profile-and-summary-reports/quickstats-about-nationalhighlights/age-and-sex.aspx

Statistics New Zealand (2013b) QuickStats about housing, http://www. stats.govt.nz/Census/2013-census/profile-and-summary-reports/ quickstats-about-housing.aspx

Statistics New Zealand (2014) New Zealand period life tables: 2010-12, http://www.stats.govt.nz/browse_for_stats/health/life_expectancy/nzperiod-life-tables-info-releases.aspx

Stroombergen, A. (2013) The Sustainability of New Zealand Superannuation: getting the starting point right, Wellington: Infometrics Ltd for Financial Services Council

Waldegrave, C. and M. Cameron (2009) 'Income, assets, living standards and housing', in P. Koopman-Boyden and C. Waldegrave (eds), Enhancing Well-being in an Ageing Society, Lower Hutt: Population Studies Centre, University of Waikato, and Family Centre Social Research Unit

Waldegrave, C., R. Stephens and P. King (2003) 'Assessing the progress on poverty reduction', Social Policy Journal of New Zealand, 20 (June)

Wilhelmson, K., C. Andersson, M. Waern and P. Allebeck (2005) 'Elderly people's perspectives on quality of life', Ageing and Society, 25, pp. $585-600$ 